\title{
HIGHER ORDER THINKING IN EDUCATION
}

\author{
Bhawani Prasad Mainali \\ Department of Education, TU, TRM Campus, Birganj \\ Bhawanimainali@gmail.com
}

\begin{abstract}
The purpose of this article is to focus on pedagogical process that can be utilized to develop in students higher order thinking skills considered necessary for quality of life. Moreover, it also describes the rationale of developing higher order thinking skills and its implications in educational context.
\end{abstract}

\section{Keywords}

Higher order thinking (HOT), critical thinking, active learning, quality education, stakeholders.

\section{Introduction}

Students lack the capacity to take knowledge acquired in one setting and apply it appropriately in a different setting. Our schools and colleges prepare students to be good citizens and good factory workers. Students were expected to sit, listen and do exactly as they are told. In some respect, this model served schools and colleges graduates well since they learned to follow direction in ways that would be valuable to their future employers.

As economic and technological changes shape the occupational outlook of today's students, schools and colleges have begin to embrace the need to instill higher order thinking (HOT) to prepar the $21^{\text {st }}$ century workforce.
No longer it is enough for school and college graduates simple to know basic facts and skills. To be successful, students must master in decision making, prioritizing, strategizing and collaborative problem solving.

Learning is more important than teaching. Teaching effectiveness depends not just on what the teacher does, but rather on what the student does. Teaching involves listening as much as talking. It is important that both teachers and students are involved in active thinking, but most important is what goes on in the students mind (Mckeachie \& Svinicki, 2006). Teaching students how to maximize their thinking potential is therefore not straight forward. Often in education, we become so focused on 'what' students 
must learn that we forget 'how' best to ensure they learn pedagogy in classroom can fundamentally affect the nature of thinking in which students engage in schools and colleges. It considers the way in which the students mind respond to the learning environment created by teachers and peers.

Recently, Anderson \& Krathwohl (2001) have revised Bloom's taxonomy to improve its pedagogical utility and accuracy. Anderson team recognized that knowledge was not really a process, as originally proposed in the taxonomy, but the context in which thinking takes place. It means HOT is important in pedagogical process (cited in Mckeachie \& Svinicki 2006: 320). The new ways of studying classroom behavior have made the studentstudent and teacher-student interaction in the classroom as the focus of effective teaching. Thus, linking teacher behavior with students performance. The new direction in education is emphasis on HOT skills in classroom teaching learning situation HOT skills is more authentic because it is relevant to the real world.

Persons who study and teach critical thinking and active learning organize goals for teaching and learning is to create types or categories of question and teaching objectives. The idea is that simply remembering some fact is very low level question and objective. At the other hand, the high level act of creating new ideas or making new interferences which enhance quality education . While there is need to work at all levels, by going beyond questioning that require simple memory or recall, we as teacher, help students tap higher level of critical thinking skills, even as they develop factual knowledge. The level, type and structure of questions are important to the discussion in classroom teaching learning process. Higher order level questions are those that ask how and why something happens or how one event, object or idea might be related to other events, objects or ideas. This process is vital for quality education.

\section{Basic concept of higher order thinking}

Thinking is a cognitive process. Higher Order Thinking (HOT) includes critical, logical, reflective, metacognitive and creative thinking. They are activated when individuals encounter unfamiliar problems, uncertainties, questions or dilemmas. The National Research Council (1987) describes HOT as a thinking that involves: problem solving where multiple solutions are possible, paths of action for solving problem that are not specified in advance (creative problem solving), considerable mental energy directed toward problem solving, subtle less than obvious decisions about strategies, transferable some criteria to the problem solving process, problems that do not provide a clear starting point, some degree of metacognition and self awareness, development and application of new theories onto sets of facts and problems.

Overall, HOT means handling a situation that we have not encountered before and is generally recognized as some combination of the above characteristics. It is thinking that happens in analysis, synthesis and evaluation levels of Bloom's taxonomy and analyzing, evaluating and creating levels of Anderson's revised Blooms taxonomy. In contrast, lower order thinking is simple, transparent and certain. In Bloom's taxonomy, knowledge, comprehension, and application and Anderson's remembering, understanding and applying are lower order thinking.

Students are engaged in HOT when they: visualize a problem by diagramming it, separate relevant from irrelevant information in a word problem, seek reasons and causes, justify solutions, see more than one side of a problem with sources of information based on their credibility, reveal assumptions in reasoning and identify bias or logical inconsistencies.

Although, some critical mass of lower order thinking in the class room is necessary as a foundation for reaching HOT skills, lower 
order skills are easier to understand, easier to teach, easier to test, easier to learn. So, why do we want to leave this comfort zone to reach for HOT skills?

Pedagogy is a word that describes the art of teaching. Most teachers strive to become better and perfect the art. A strong pedagogy necessitates the study of teaching methods that include the study of specific ways in which teaching goals may be achieved. One of the most common goals of teaching is to develop critical thinking skills in students. This higher level thinking is what that allows students to excel and achieve intellectual freedom.

\section{Rationale behind HOT}

We should manage HOT skills in the classroom teaching learning process because they have enormous benefits for learners. The reasoning is similar to the rationale for pushing knowledge into our long term memory. First of all, information learned and processed through HOT processes is remembered longer and more clearly than information that is processed through lower order rote memorization. Moreover, the student with the deeper conceptual knowledge will be better able to access that information for use in new contexts. This may be the most important benefit of HOT.

Knowledge obtained through HOT processes is more easily transferable, so that student with a deep conceptual understanding of an idea will be much more likely to be able to apply that knowledge to solve new problems in different situations. HOT transfer of understanding is the key to good thinking and problem solving. Good thinking and problem solving skills make learned knowledge applicable in the real world. As a result, quality of education is increased.

If we teach students to read and write, provide them with factual information, but do not equip them with the cognitive high level thinking skills to understand appreciate and transfer or connect ideas, then the information they have may be meaningless in future. Nurturing high level thinking skills that enable students to synthesize meaning or apply ideas to other contexts are key. We are living in a rapidly changing world and finding that our low level thinking is inadequate to meet demands put upon it. It is often said that we should try to provide equal opportunity and equity to all groups of people to bring the mainstream of society through education. It is possible through HOT skills in education. HOT provides a better understanding of a learners centered education.

With the growing complexities of the modern world, the importance of learning is increasing day by day. The problems are complex and they require specialized attention. So unless people are trained at high levels of competence, it is difficult to meet the requirement of the modern world. In the present context of globalization and competition, we require high level thinking skills in education to adjust in different situations. HOT emphasizes students' real learning achievement and practical implication of education which is vital. Thus, HOT is beneficial for all stakeholders of education in society to promote four pillars of learning (learning to know, learning to do, learning to be and learning to live together). Active learning can make a course more enjoyable for both teachers and students and most importantly, can cause students to thinking at higher level.

\section{HOT in Nepalese education}

Our education system rarely encourages HOT skill opportunities and practices. To improve our education system, we need to emphasize on HOT skills in classroom teaching learning process. Unfortunately the current teaching learning situation in classroom is not really supporting in that direction. We are more often engaged in low level thinking skills for transmitting simple factual information.

In the past few decades, widespread 
dissatisfaction with the performance of students has produced new pressures for educators to adapt HOT Skills. In Nepalese education system, students' learning achievement and their ability is tested only marks obtained in examination and interpret the good student who achieve high marks and the poor student who obtained low marks. Here, to achieve high marks, student may rote the content only or transfer only factual information is ignored. In contemporary society, the major aspect of learning is workable ability of learners which is not focused in our education system.

Nowadays education is considered as an empowerment process. Transforming society through education is possible only when we use HOT skills in education. Therefore, it is necessary that stakeholders of education are made aware of HOT. If we use HOT skills in teaching learning situation, it can provide broad base of education.

\section{Strategies to develop HOT in education}

The importance of HOT makes it a priority in our classroom teaching learning process, but how HOT can be taught and its deep conceptual understanding be developed that is transferable to various academic contexts and, perhaps more importantly, to real world problem. There are various methods and strategies to develop HOT in classroom situation.

Limbach and Waugh (2009) describes fivesteps process for the development of higher level thinking skills, which are relevant to our context and can be implemented in any teaching learning situation to create a more active learning environment and to move learners towards higher level thinking. These five-steps are:

\section{Determine learning objectives}

Teacher should carefully identify key learning objectives that recognize what students should know when they exit the class. To make high level thinking happen, these learning objectives, as well as the activities and assessment, must require students to perform and demonstrate high level thinking. Thus, a well written lesson plan should target a specific behavior, introduce and practice the desired behavior and end with the learner exhibition of the behavioral response. The development of well-written objectives will greatly accelerate learners' movement into higher level thinking. Bloom's revised taxonomy of cognitive objectives is usefully in planning curriculum that incorporates low to high level thinking activities.

\section{Teach through questioning}

Questioning is a vital part of the teaching learning process. The art of questioning begin with establishing what is known and allows the teacher to extend beyond to develop new ideas and understandings. The level of student thinking is directly proportional to the level of questions asked. When the teachers plan, they must consider the purpose of each question and then develop the appropriate level and type of question to accomplish the purpose. All students need experience with higher level questioning once they become familiar with a concept. Questioning techniques can be used to foster the thinking ability of students. Questions can be categorized in a number of different ways. One simple method is to use the general categories of convergent questions and divergent questions. Convergent questions seek one or more very specific correct answer, while divergent questions seek a wide variety of correct answers. Convergent questions apply to Bloom's lower level and divergent question apply to Bloom's higher level objectives. Andre (1987) concluded that questions generally do aid learning and that high level questions rather than low level factual questions, increase the effectiveness of student processing of learning (cited in McKeachie, et al. $2006:$ 32). Thus, teachers should use questioning techniques to inspire higher level thinking in the classroom. 


\section{Practice before assessment}

To make learning more active, teachers need to add experiential learning and opportunity for reflective dialog. Practice is necessary to master any skill, students must have the opportunity to practice the knowledge, skills, attitudes and behaviors that will be evaluated. Therefore, choosing learning activities that allow them to practice is important. For students to participate in higher level thinking, they must pose arguments, state opinions, look for evidence, critique the evidence and think with fair mindedness.

Review, refine and improve

Teachers should strive to continually refine their course to ensure that their instructional techniques are in fact moving students toward critical thinking. Students become responsible for their own learning when teachers monitor class activities, create a supportive environment and carefully track student participation. Collecting feedback from student about what they have, or have not learned, may present the need to offer opportunities for relearning and expose areas in need of improvement. Creating a classroom environment conducive in which all students feel good about participating is a very important step in higher level thinking. Student feedback is also an important tool to be used in the improvement of a course.

\section{Provide feedback and assessment of learning}

Feedback like assessment compares criteria and standards to students' performance is an effort to evaluate the quality of work. Prior to providing opportunities to practice what is to be assessed, it is imperative that students first understand the standards by which they will be assessed. Next, students should be provided with constructive and relevant feedback by the teacher and peers as well as assessing their own performance. Students' feedback and assessment provides an immediate and significant source of information for the outcome-based assessment process in evaluating instructional techniques students, achievement, specific learning activities, the course, departmental program etc. Comparing criteria and standards to student performance in feedback to students and assessment of course and departmental programs provide a significant source of information when determining effectiveness. Teacher feedback like assessment can be used to evaluate the students' quality of work. Teacher should provide good feedback to their students through frequent opportunities to practice whatever they are expected to do at assessment time. Teachers should spend ample time helping student to understand what the criteria and standards are and what they mean. Students' peers also provide feedback and evaluation. Each of these techniques help students learn to distinguish between satisfactory and unsatisfactory performance.

\section{Conclusion}

The successful implementation of HOT skills requires the thoughtful consideration of current instructional techniques and the commitment for active student-centered teaching learning environment. Similarly, Students also need to develop habits of reflection of thinking about their experience, success and failure, their plan and purposes. Although the use of five-step process to move students towards higher level thinking may necessitate a change in instructional techniques, effort will be beneficial to all stakeholders. We should understand that HOT is best teaching learning technique in real world contexts and by varying the scenarios students can use their newly acquired skills. We should emphasize the building blocks of HOT skills. Therefore, HOT is vital for quality education.

\section{References}

Mainali, B.P. (2011) Critical thinking for quality education. Academic Voices: A Multidisciplinary Journal, 1, 6-10. 
McKeachie, W.J. \& Svinicki, M. (2006). Teaching tips: Strategies, research $\mathcal{E}$

theory for college and university teachers. New York: Houghton Miffilin Company.

Marzano, R.J \& Kendall, J.S. (2007). The new taxonomy of education objectives. New Delhi: Sage Publication

McGregor, D. (2010). Developing thinking developing learning : a guide to thinking skills in education. New Delhi: Tata McGraw Hill.

Prakash, V. (2010). Creative learning: a handbook for teachers $\mathcal{E}$ trainers. New Delhi: Viva Books.

Limbach, B. \& Waugh, W. (2009). Developing higher level thinking. Retrieved on $24^{\text {th }}$ sept. 2012 from: abri.com/ Manuscript/ 09423 pdf. 